ESPAÇO TEMÁTICO: TRABALHO, TECNOLOGIAS DA INFORMAÇÃO E COMUNICAÇÃO E CONDIÇÕES DE VIDA

\title{
Trabalho docente na educação básica no Brasil sob indústria 4.0
}

\author{
Fabiane Santana Previtali ${ }^{1}$ \\ https://orcid.org/0000-0002-8079-5557
}

\author{
Cílson César Fagiani ${ }^{2}$ \\ https://orcid.org/0000-0002-2800-8106
}

${ }^{1}$ Universidade Federal de Uberlândia, Instituto de Ciências Sociais, Uberlândia, MG, Brasil

${ }^{2}$ Universidade de Uberaba, Programa de Pós-graduação em Educação, Uberlândia, MG, Brasil

\section{Trabalho docente na educação básica no Brasil sob indústria 4.0}

Resumo: O objetivo do artigo é analisar o trabalho docente na Educação Básica no Brasil, especialmente a partir de 2020, quando se instaura a Pandemia Covid-19, em meio à difusão do teletrabalho no bojo da Indústria 4.0, sob o aprofundamento do Neoliberalismo e da Nova Gestão Pública (NGP). A metodologia foi baseada em estudos bibliográficos, documentais e relatórios de pesquisas, bem como análise de dados do Instituto Brasileiro de Geografia e Estatística (IBGE) e Instituto Nacional de Estudos e Pesquisas Educacionais Anísio Teixeira (INEP), em períodos selecionados. Os resultados indicam a difusão do teletrabalho sob o neoliberalismo e a NGP, implicando no aprofundamento da já precarizada carreira do profissional docente sob a pandemia.

Palavras-chave: Indústria 4.0; Neoliberalismo; Trabalho Docente; Educação Básica; Pandemia Covid-19.

Teaching work in basic education in Brazil under industry 4.0

Abstract: The objective of the article is to analyze the teaching work in Basic Education in Brazil, especially from 2020, when the Covid-19 pandemic was declared, boosting the diffusion of telework in the context of Industry 4.0, the deepening of neoliberalism and the New Public Management (NGP). The methodology was based on bibliographic, documentary and research reports, as well as data analysis from the Brazilian Institute of Geography and Statistics (IBGE) and National Institute of Educational Studies and Research Anísio Teixeira (INEP), in selected periods. The results indicate the spread of telework under neoliberalism and NGP, implying the deepening of the already precarious career of professional teaching under the pandemic.

Keywords: Industry 4.0; Neoliberalism; Teaching work; Basic education; Covid-19 pandemic.

Recebido em: 29.06.2021. Aprovado em: 08.09.2021. Revisado em: 14.09.2021. 


\section{Introdução}

Logo na primeira década do século XXI, em 2008, o mundo experimentou a emergência de mais uma crise estrutural do capitalismo e, mais uma vez, desde a reestruturação produtiva do capital em fins dos anos 1970, seus defensores adotaram as mesmas medidas: mais mercado, menos Estado Social, mais devastação ambiental e destruição dos direitos sociais adquiridos pela classe trabalhadora (HARVEY, 2011; HARVEY, 2018). Esse receituário neoliberal foi amplamente difundido no mundo globalizado, em maior ou menor grau, a depender, por um lado, das lutas sociais entre trabalho e capital em cada país e, por outro, da posição geopolítica dos países na divisão internacional do trabalho. Ante o neoliberalismo, aprofundam-se reformas do Estado sob os princípios da Nova Gestão Pública (HOOD, 1995) ou Gerencialismo (NEWMAN; CLARKE, 2012; Hall; GUNTER, 2015), cuja ênfase incide nos processos de privatização e terceirização de forma a tornar serviços públicos nichos de negócios para o capital.

Nesse contexto, ao qual se acrescenta o avanço das novas tecnologias informacionais-digitais, diversos autores (KALLEBERG, 2009; HUWS, 2013; SOTELO, 2016; ALBERTI, et al, 2018; HASSARD; MORRIS, 2018; ANTUNES, 2018; 2020), têm apontado mudanças na estrutura do trabalho e do emprego, acompanhadas por desemprego e por crescentes níveis de precarização das condições de vida da classe trabalhadora. Para Alberti et al (2018), a questão da precariedade da classe trabalhadora volta à baila, agora acrescida de algo novo: a perda de controle sobre um futuro que antes parecia estar sob controle, com mais e mais áreas da vida sendo subordinadas às necessidades da economia. Hassard e Morris (2018), chamam a atenção para aqueles segmentos mais jovens da classe trabalhadora, com maior nível de escolaridade e mais profissionalizados academicamente que se veem à mercê da instabilidade e da insegurança. Para Antunes (2018; 2020), o que se verifica atualmente na era do capitalismo de plataforma é a ampliação da classe trabalhadora no mundo sob a crescente parcela do novo proletariado de serviços da era digital.

Vale dize que a pandemia do Covid-19 tende a se aprofundar nesse quadro em que neoliberalismo e Indústria 4.0 se articulam e se retroalimentam. O primeiro caso de Covid-19 foi registado foi em 25 de fevereiro de 2020 e o governo Bolsonaro (2018 -) vem desconsiderando as medidas de isolamento e a aquisição de vacinas, conforme apuração em andamento na Comissão Parlamentar de Inquérito $(\mathrm{CPI})^{1}$, instaurada para investigar as ações do governo federal quanto à pandemia. O presidente chegou a chamar a doença de gripezinha e afirmou, em pronunciamento nacional, que as pessoas saíssem do isolamento e fossem trabalhar e, quando questionado por jornalistas sobre o número crescente de mortes, ele respondeu: "E daí? Lamento, quer que eu faça o quê?" (REVISTA..., 2020). O país tem o maior número de casos por Covid-19 na América Latina com 16.977.062 infecções e 472.531 mortes registradas desde o início da pandemia até 06 de junho de 2021 (REUTERS, 2021).

Sob a pandemia em 2020, o país atingiu a taxa de 11,9 milhões de desempregados, número esse elevado a 14,7 milhões no primeiro trimestre de 2021, um crescimento de 2,9 milhões de pessoas (IBGE, 2021). A vulnerabilidade da classe trabalhadora ao vírus potencializa os casos de Covid-19 no país e lança luzes sobre as enormes discrepâncias sociais, a concentração da renda e o concomitante aumento da pobreza e o escarnio com que essas questões são tratadas no âmbito do neoliberalismo.

A educação escolar não está alheia a esse cenário e as normativas educacionais sob a pandemia impactam drasticamente a comunidade escolar, envolvendo familiares, estudantes e professores. Com a pandemia do Covid-19, o Ministério da Educação autorizou, em 18 de março de 2020, a adoção do ensino remoto e do teletrabalho docente em substituição as aulas presenciais (LIMA, 2020). Essa medida se deu sob forte contestação dos professores e demais profissionais da educação e seus sindicatos, em especial na esfera pública, considerando-se a forma aligeirada, sem um debate aprofundado sobre as garantias de acesso de professores e estudantes às tecnologias digitais e desconsiderando as condições estruturais de trabalho e de vida da classe trabalhadora sob a pandemia, portanto, comprometendo o alcance e a eficácia da nova modalidade para o processo de ensino e aprendizagem (LEHER, 2020; PREVITALI; FAGIANI, 2020a).

A Educação Básica é particularmente atingida pois trata-se do processo de ensino e aprendizagem de crianças e jovens dos 4 aos 17 anos. Fagiani (2018) considera essa etapa educacional decisiva para o processo formativo do ser humano e os estudantes são dependentes das orientações dos professores, mais ainda quando estão nos anos iniciais, fase de alfabetização. Para o autor, os professores devem possuir condições de trabalho adequadas e sólida qualificação profissional, envolvendo conhecimentos e habilidades específicas, que permitam 
a escolha de conteúdos e metodologias específicas, os quais não devem ser padronizados, considerando-se as peculiaridades de cada criança e, no caso do teletrabalho no ensino remoto, esse conjunto de variáveis é suprimido.

Partindo dessas ponderações, o objetivo do artigo é analisar o trabalho docente na Educação Básica no Brasil, especialmente a partir de 2020, quando se instaura a Pandemia Covid-19, em meio à difusão do teletrabalho no bojo da Indústria 4.0, sob o aprofundamento do Neoliberalismo e da Nova Gestão Pública (NGP). A metodologia foi baseada em estudos bibliográficos, documentais e relatórios de pesquisas, bem como análise de dados do Instituto Brasileiro de Geografia e Estatística (IBGE) e Instituto Nacional de Estudos e Pesquisas Educacionais Anísio Teixeira (INEP), em períodos selecionados. Os resultados indicam a indissociabilidade entre capitalismo neoliberal, NGP e tecnologias digitais, implicando no aprofundamento da já precarizada carreira do profissional docente sob a pandemia.

O artigo está organizado em duas seções, além da introdução e das considerações finais. A primeira seção analisa a Indústria 4.0 na Educação Básica e seus impactos nas condições do trabalho docente. A segunda seção chama atenção para a difusão do ensino remoto e do teletrabalho no bojo da pandemia Covid-19 e suas consequencias para o trabalho docente. Nas considerações finais buscou-se demarcar as questões centrais do artigo no seu conjunto.

\section{Indústria 4.0 e Educação Básica: o teletrabalho docente}

A Indústria 4.0 consiste em mais uma etapa no avanço sociotécnico sob a determinação da produção do valor de troca. Para Grohmann (2020), esse processo de organização e sistematização dos dados não é neutro, mas está circunscrito à lógica da expropriação e acumulação do capital em sua fase neoliberal e financeira, consolidando uma nova etapa de acumulação do capital. Nesse sentido, a tecnologia é produto das relações sociais de classe é possui uma determinação de classe.

Para Woodcock (2020, p. 30-31), as tecnologias informacionais-digitais representam um novo modelo de gestão que "faz parte de uma longa história de gestão do trabalho, um processo que envolve, impreterivelmente, tentativas de supervisionar, controlar, motivar e disciplinar os trabalhadores". Assim, o que a classe trabalhadora vivencia hoje, sob a Quarta Revolução Industrial ou Indústria 4.0, é a substituição de operações mentais humanas pelas máquinas e a tentativa de ocultamento da relação de exploração entre capital e trabalho por meio da mediação tecnológica.

A Indústria 4.0 traz consigo o advento do teletrabalho ou trabalho virtual ou ainda trabalho digital, modalidade laboral em que a comunicação do trabalhador com a empresa, ou com o tomador dos serviços, envolve, primordialmente, transferências de informações codificadas sob forma eletrônica, fazendo-se uso das novas tecnologias informacionais e de comunicação, sob a forma de plataformas digitais (Apps) (CARUSO, 2020). Para Caruso (2020), o trabalho digital é dotado de grande flexibilidade ao poder ser realizado em qualquer lugar: em domicílio, em locais públicos, como praças ou shoppings centers, em salas compartilhadas por trabalhadores, de forma itinerante, em carros, motos, bicicletas, e até mesmo a pé, desde que haja um computador ou celular e conexão de internet.

A grande flexibilidade ofertada ao capital é sinônimo de precarização para a classe trabalhadora que vivencia a perda de direitos sociais historicamente conquistados em meio a reformas trabalhistas que promovem contratos de trabalho precários e até mesmo nenhum contrato, sob a mediação das plataformas digitais, como no caso dos trabalhadores uberizados. Para Antunes (2020, p. 11), “a uberização é um processo no qual as relações de trabalho são crescentemente individualizadas e invisibilizadas, assumindo assim, a aparência de 'prestação de serviços' e obliterando as relações de assalariamento e de exploração". O trabalho uberizado em expansão se funda numa aparente relação de não-trabalho e, portanto, de não exploração dada a indeterminação entre o tempo do trabalho e o tempo do não-trabalho sob a aparência de mais liberdade e menos controle e imposições.

A educação escolar não está alheia às mudanças no mundo produtivo e a escola cumpre um papel essencial na habituação do ser social para o trabalho abstrato (ENGUITA, 1989; BOURDIEU; PASSERON, 2013). Por outro lado, Gramsci (1976) já enfatizava que a formação da consciência de classe não seria formada naturalmente e daí a relevância dos intelectuais, principais agentes dessas mudanças, e da escola, como um 
dos seus instrumentos mais importantes, promovendo a elevação cultural das massas e possibilitando uma interpretação crítica da ideologia das classes dominantes por meio de uma prática social transformadora.

É nesse sentido que se pode conceber a educação materializada na escola como resultante das lutas sociais que emergem no local de trabalho, num processo histórico e dialético (SAVIANI, 2007; 2015). Nessa perspectiva, a escola, enquanto local de trabalho, se torna, um terreno contestado (EDWARDS, 1979), sendo palco de conflitos e disputas político-ideológicas sobre os meios e os fins da educação, ou seja: se uma educação escolar voltada para o pleno desenvolvimento da pessoa humana ou se para uma qualificação profissional restrita, vinculada às ocupações no mercado de trabalho.

Importa dizer que a escolarização e a qualificação profissional são categorias históricas e estão relacionadas às mudanças técnicas e/ou organizacionais determinadas pela lógica da acumulação do capital. Assim, uma vez implementadas as mudanças no processo de trabalho, as habilidades e conhecimentos do trabalhador tendem a se tornar obsoletos, impelindo-o à aquisição de novas qualificações mais adequadas ao novo patamar técnico.

Previtali e Fagiani (2015) argumentam que a escolarização e a qualificação profissional devem ser compreendidas no âmbito das relações de classe e trazem em si uma contradição: por um lado, expressam a qualificação da força de trabalho como mercadoria necessária à produção e reprodução do capital, um fator de produção para o crescimento econômico e atendimento das exigências do mercado, conforme a ideologia do capital humano e da meritocracia (RAMOS, 2011; SHIROMA; EVANGELISTA, 2011; FRIGOTTO, 2020) e, por outro, para a classe trabalhadora, elas permitem a aquisição de conhecimentos e técnicas que possibilitam a real compreensão do modo de funcionamento da sociedade burguesa e seus antagonismos, contribuindo, dessa forma, para a construção de uma subjetividade crítica e radical de transformação social, portanto, vinculada a uma formação humana dotada de sentido para além do trabalho alienado (GRAMSCI, 1976; SAVIANI, 2007; 2015).

Num contexto de aprofundamento do neoliberalismo e da NGP no Brasil (OLIVEIRA, 2015), especialmente a partir da posse de Michel Temer (2016-2018) no bojo do golpe institucional à presidenta Dilma Rousseff (2014 - 2016), as políticas educacionais implementadas indicam o caminho da qualificação profissional imediata, empurrando precocemente os estudantes da classe trabalhadora que frequentam a escola pública para os postos mais precarizados do mercado de trabalho e aprofundando a educação dual no país (FERRETTI, 2018; FAGIANI, 2018; FRIGOTTO, 2020; PREVITALI; FAGIANI, 2020a). Concomitantemente à reforma curricular, escolas públicas têm sido fechadas com vistas à redução de recursos, utilizando-se para tanto, índices de avaliações de desempenhos quantitativos de estudantes e professores (EVANGELISTA; LEHER, 2012; FREITAS, 2016), iniciativas essas que contribuem para a intensificação do trabalho docente, pois aumentam o número de estudantes por turma/professor. Ao mesmo tempo, com menos recursos, as condições de infraestrutura das escolas passam a ser negligenciadas.

Segundo Tokarnia (2020), em 2019, 3,5 mil escolas públicas não tinham banheiros, o que representava 2,4\% do total, passando para 4,3 mil, 3,2\% do total em 2020. No país, menos da metade das escolas públicas, ou seja, 46,7\%, tem acesso a saneamento básico, o que tem levado à diversas manifestações de sindicatos dos profissionais da educação sobre a necessidade do poder público garantir a educação escolar com padrão de qualidade universal, conforme a Constituição Federal de 1988 (BRASIL, 1988) e a Lei de Diretrizes e Base de 1996 (BRASIL, 1996), seja ela presencial ou remota (PREVITALI; FAGIANI, 2020a).

Os docentes inserem-se no contexto escolar da Educação Básica de forma particular, pois são, ao mesmo tempo, formados pelo sistema educacional e principais formadores no processo escolar, sendo responsáveis pela formação da classe trabalhadora. Conforme Saviani (2007 e 2015), a educação é um fenômeno próprio dos seres humanos e a compreensão da natureza da educação passa pela compreensão da natureza humana que se funda na relação do ser humano com o mundo exterior, num processo histórico e dialético de transformação da natureza e do próprio ser humano pelo trabalho dotado de intencionalidade. Assim, a educação não significa apenas transmissão de conhecimento, mas a própria produção do ser social. Diante disso, o controle do trabalho docente, em seus aspectos objetivos e subjetivos, torna-se peça fundamental para a reestruturação neoliberal da Educação Básica.

De acordo com o INEP (2020), a Educação Básica possui um total de 2.189.005 docentes, sendo 1.711.932 na administração pública e 547.863 na administração privada. O corpo docente da Educação Básica no Brasil é majoritariamente feminino, correspondendo a mais de $80 \%$ da força de trabalho (INEP, 2020). Ressalta-se também uma significativa presença da faixa etária mais jovem. Em 2017, 63\% da força de trabalho 
na carreira docente, com idade até 29 anos era feminina, sendo que na região Sudeste ${ }^{2}$, a qual concentra os estados mais populosos e economicamente importantes do país, essa porcentagem era de 79\% (PREVITALI; FAGIANI, 2020b). Segundo pesquisa da GESTRADO (2020), realizada com 15.654 docentes da Educação Básica da rede pública em 2020, as mulheres representavam 78\% dos respondentes, sendo que a metade estava com idade entre 30 e 49 anos.

No que tange as relações laborais, destaca-se que, dos docentes na administração pública, 1.195.232 são concursados, possuindo, portanto, estabilidade funcional, planos de carreira definidos e direitos trabalhistas assegurados. No entanto, as reformas neoliberais sob a NGP têm promovido a adoção de formas precárias do trabalho. Dados do INEP (2020) mostram que 543.874 docentes estão sob contratos temporários, sendo 55\% nos municípios e $46 \%$ nos estados. E ainda, 5.626 encontram-se sob contratos terceirizados, sendo 85,5\% nos municípios e $11,7 \%$ nos estados e 36.582 estão sob regime de contrato CLT $^{3}$, sendo $65,9 \%$ municípios e $33,9 \%$ nos estados. Conforme Previtali e Fagiani (2020b), entre os anos 2011 e 2019 houve um aumento de $19 \%$ dos docentes com vínculo contratual temporário no Brasil e de $28 \%$ na região Sudeste, sendo que no estado de Minas Gerais, um dos primeiros a adotar a $\mathrm{NGP}^{4}$, o aumento dos contratos temporários foi de $61 \%$ no período considerado.

Ao mesmo tempo em que ocorre o aumento dos contratos temporários, observa-se o crescimento de professores em caráter eventual ou intermitente, modalidade esta que não possui nenhum tipo de contrato, sendo que o professor ministra aulas em caráter emergencial (SOUZA, 2016). Se essa modalidade sempre esteve presente na carreira docente, sob as tecnologias digitais elas tendem à expansão com professores eventuais sendo contratados através de plataformas digitais e aplicativos (apps), num formato similar ao da empresa Uber (VENCO, 2019). Um exemplo de trabalho docente uberizado é a Biosferatech ${ }^{5}$, empresa de tecnologia, que desenvolveu o app Prof- $e^{6}$, Plataforma Colaborativa de Professores por Demanda para as escolas da Educação Básica. Nessa nova - e precária - modalidade de trabalho, o professor faz seu cadastro no app, e, se aprovado, pode ser chamado para substituir aulas presenciais (se for na cidade onde reside) ou de forma remota em qualquer cidade do Brasil, com educação à distância invertida, isto é, estudantes na escola e professor à distância (PREVITALI; FAGIANI, 2020b).

Ainda concernente às relações laborais, cumpre destacar que o salário pago ao professor na Educação Básica tende a ser menor que o de outros profissionais com nível de formação equivalente (ALVES; PINTO, 2011). Atualmente, embora haja a obrigatoriedade, em nível nacional, do pagamento do piso salarial mínimo de $\mathrm{R} \$ 2.886,24$ por $40 \mathrm{~h} / \mathrm{semanais}$ ao professor da Educação Básica pública, apenas cerca de $45 \%$ dos 5.570 municípios brasileiros cumprem essa determinação (GOTTI, 2019).

Se a precarização das escolas públicas e da Educação Básica, assim como do trabalho decente já vinham ocorrendo no bojo do aprofundamento do neoliberalismo e da NGP que busca transformar serviços públicos em negócios, sob a pandemia esse cenário foi, além de explicitado, acrescido de novos elementos dada a implementação do ensino remoto e do teletrabalho docente.

\section{Teletrabalho Docente: o futuro da Educação Básica?}

Sob a pandemia do Covid-19 e a necessidade do isolamento social, uma nova modalidade de trabalho docente teve início em 18 de março de 2020 na Educação Básica, o ensino remoto emergencial (ERE) por plataformas e aplicativos sem que fosse estabelecido um debate amplo e aprofundado com os profissionais da educação e a comunidade escolar acerca de seu alcance com equidade de condições de acesso, num contexto de aprofundamento da precariedade das condições de trabalho e de vida da classe trabalhadora. Importa frisar que a adoção dessa modalidade de ensino se deu num contexto em que 55,9\% dos domicílios particulares no país não tem computadores e, dentre aqueles que possuem internet, 99,2\% o fazem apenas pelo celular (IBGE, 2020). Vale lembrar que os professores da Educação Básica estão incluídos nesse quadro, sendo que 9 a cada 10 professores utilizam o telefone celular para a realização das aulas remotas (GESTRADO, 2020).

Segundo pesquisa realizada pela Gestrado (2020), com 15.654 professores da Educação Básica pública no período de 8 a 30 de junho de 2020, os aplicativos foram utilizados por $42,9 \%$ das redes municipais e por $75,2 \%$ das redes estaduais de ensino. Pesquisa realizada pela Nova Escola (BIMBATI, 2020), com 9.557 professores, sendo $85,7 \%$ deles professores da Educação Básica e 76,6\% da rede pública, demonstrou que a plataforma 
mais utilizada pelos professores para comunicação com as famílias dos estudantes foi o WhatsApp $(65,3 \%)$, seguida do Facebook (36,4\%).

Seguindo as orientações do Ministério da Educação, as secretarias estaduais e municipais de educação começaram a exigir de professores a elaboração de tutoriais para orientação de estudantes e para orientação de pais e responsáveis sobre como auxiliar as crianças nas atividades em casa, além da elaboração das planilhas virtuais de conteúdo para estudantes via sites, e-mail e aplicativos para os pais e responsáveis cadastrados nas escolas. No caso do estado de Minas Gerais, as novas exigências ocorreram em um contexto de greve da categoria, desde o início do ano letivo de 2020, pelo pagamento do Piso Nacional da Educação e do $13^{\circ}$ salário de 2019, reivindicando-se ainda a isonomia salarial com outras categorias profissionais (PREVITALI; FAGIANI, 2020a).

Destaca-se que $84 \%$ dos professores da Educação Básica pública não tinham experiência alguma com aulas remotas e houve pouca atenção dos governos em atentar para esse fato (GESTRADO, 2020). Conforme a Gestrado (2020), 53,6\% dos professores das redes municipais de ensino e 24,6\% dos professores das redes estaduais de ensino afirmaram não receber nenhum tipo de formação ou auxílio para o uso das tecnologias digitais. Na pesquisa realizada pela Nova Escola (BIMBATI, 2020), mais de 50\% dos professores disseram não ter recebido capacitação para trabalhar com o ensino remoto.

O depoimento de uma professora é ilustrativo desse cenário: "Tenho trabalhado com o que já conhecia ou buscando o que não conhecia" (BIMBATI, 2020, p. 1). Em outro depoimento, um professor afirma ter arcado ele mesmo com as despesas para ter melhores condições de trabalho:

Adquiri um novo celular com memória maior, webcam, fone de ouvido, ampliei memória do meu notebook. Tenho contado muito com a ajuda de alguns colegas que dominam melhor estas novas tecnologias. Acompanho também lives e palestras online. (BIMBATI, 2020, p. 1)

Outro ponto importante quanto ao ensino remoto diz respeito ao argumento disseminado por empresas educacionais e pela grande mídia, de que ele possibilita maior tempo livre ao professor. No caso do trabalho docente essa informação não se confirmou. Na verdade, o teletrabalho docente na Educação Básica no Brasil tem implicado em mais horas trabalhadas, pois passa a envolver atividades de cunho informacional-digital complexas que fogem à formação profissional. As atividades de organização, planejamento e realização das aulas, bem como o processo avaliativo, que fazem parte do trabalho docente, devem agora ser adequadas ao ambiente virtual. Dentre as novas atividades estão a de planejar as atividades nos apps, acompanhar a presença e a aprendizagem dos/as discentes à distância e orientar as famílias para realizarem atividades com as crianças em casa nos apps.

Acrescenta-se a esse conjunto de atividades ligadas à docência, a necessidade de aprender e de se adaptar à linguagem da web. Essa nova situação tem aumentado a jornada de trabalho e tornado maior a indeterminação entre o tempo do trabalho e o tempo do não-trabalho, implicando na redução de tempo de descanso na jornada de trabalho, gerando estranhamento e adoecimento e contribuído para precarização do trabalho docente. Segundo a Gestrado (2020), aproximadamente 75\% dos professores da Educação Básica apresentaram a percepção de que houve um aumento nas horas trabalhadas no ensino remoto. Importa frisar que esses elementos tendem a se tornar ainda mais expressivos para as mulheres, dado que elas permanecem responsáveis pelas atividades do cuidado na esfera reprodutiva no bojo da divisão do trabalho sob o capital.

No contexto pandêmico, os professores foram constrangidos a se reiventar para as aulas virtuais, a partir de seus próprios esforços e recursos, arcando com as despesas financeiras quanto à aquisição de equipamentos e/ou melhorias em sua rede de internet. O teletrabalho remoto levou à redefinição do espaço da casa como também espaço do trabalho, implicando numa jornada de trabalho ainda maior em função das atividades domésticas, impactando significativamente na saúde mental desses profissionais, em especial das mulheres, que compõem a grande maioria da força de trabalho na Educação Básica. Diz uma professora:

Sou mãe de uma criança de 2 anos. Eu e meu marido estamos trabalhando home office. Tentamos dividir as responsabilidades, mas a maior parte sempre cai para mim. E por trabalhar mais que a minha carga horária normal, tivemos conflitos graves, pensamos até em separação, por eu ter que dar uma maior atenção ao trabalho. (BIMBATI, 2020, p. 1). 
Segundo a Nova Escola (BIMBATI, 2020), 66\% dos/as professores/as precisaram se afastar do trabalho por questões de saúde, com destaque para os casos de ansiedade (68\%), estresse e dor de cabeça (63\%), insônia (39\%), dores nos membros (38\%) e alergias (38\%). Os relatos evidenciam preocupações advindas da dupla jornada, especialmente das professoras, como a dificuldade de conciliar as atividades domésticas com as profissionais e de acompanhar e apoiar os estudos dos filhos em idade escolar. Na avaliação da saúde emocional comparada ao período pré-pandemia, em uma escala de 0 a 10, sendo 0-2 péssima, 3-4 ruim, 5-6 razoável, 7-8 boa e $9-10$ excelente, $10 \%$ dos professores afirmaram que se encontravam na forma péssima, $18 \%$ na forma ruim, $30 \%$ na forma razoável, $27 \%$ na forma boa e $8 \%$ na forma excelente (BIMBATI, 2020). Ou seja, 65\% dos professores tiveram sua saúde emocional prejudicada com o teletrabalho e o ensino remoto na pandemia.

Ao mesmo tempo as horas de trabalho aumentam e as condições laborais se tornam ainda mais precarizadas e levam os docentes ao adoecimento, as administrações municipais e estaduais e as escolas particulares, se valendo das novas regras laborais sob a pandemia, impõem redução salarial e encerraram contratos de trabalhos dos docentes. Segundo uma professora: "Meu salário diminuiu para R \$221. A escola tem feito da gente o que quer, porque precisamos do nosso trabalho" (BIMBATI, 2020, p. 1). Na cidade Lagoa Formosa, no estado de Minas Gerais, os professores tiveram seus contratos temporários de trabalho rescindidos no mês de abril de 2020 pela Secretaria Municipal de Educação, numa comunicação por WhatsApp, em virtude da suspensão das aulas presenciais (PREVITALI; FAGIANI, 2020a).

Outro elemento de atenção nesse contexto pandêmico é que, sob o ensino remoto e o trabalho sendo realizado na esfera doméstica, presencia-se um terreno fértil para o crescimento da individualização do trabalho e o esgarçamento do sentimento de solidariedade de classe, contribuindo para maiores dificuldades às organizações e ações coletivas contrárias à precarização.

\section{Considerações Finais}

A Indústria 4.0 representa o mais novo patamar de desenvolvimento sociotécnico da sociabilidade humana sob a vigência do capital. Nesse sentido, não é qualquer tecnologia que será desenvolvida sob a exploração do trabalho vivo, mas aquela que irá gerar mais valor. Por sua vez, o mais valor será melhor realizado quanto maior for o controle sobre o trabalho. Nesse contexto, impõe-se à classe trabalhadora a precarização da vida, sob o aprofundamento do neoliberalismo e da NGP que, através de privatizações e terceirizações, visa tornar os serviços públicos nichos de negócios do capital e o trabalho meio de extração de mais-valor. A NGP na Educação Básica pública tem promovido a utilização crescente de contratos temporários de trabalho e até mesmo de ausência de contratos, em detrimento de formas mais estáveis de emprego.

Sob a pandemia do Covid-19, em 2020, observou-se a imposição do teletrabalho docente na Educação Básica pelo poder público, sem a interlocução com a comunidade escolar e à despeito das considerações dos professores e demais profissionais da educação quanto às condições de acesso dos estudantes à modalidade remota, bem como quanto às novas condições do trabalho docente. Destaca-se que o corpo docente na Educação Básica no Brasil é majoritariamente feminino, o que submete as professoras à ainda maiores e mais intensivos níveis de subordinação e precarização laboral dado que são as mulheres as responsáveis pela maioria das tarefas domésticas e de cuidado da família.

Pode-se afirmar que o ensino remoto e o teletrabalho estão implicando no aprofundamento das desigualdades educacionais e sociais na Educação Básica e ocorrem sob forte direcionamento da NGP que, por sua vez, estimula e viabiliza a presença de empresas educacionais privadas na educação pública, a vender plataformas e conteúdos, num processo crescente de subordinação da Educação Básica pública aos interesses mercadológicos e ideológicos privados.

No entanto, cabe ressaltar que a organização e resistência dos professores contra a precarização e degradação do trabalho é um processo histórico, inerente à própria relação trabalho-capital. No caso da Educação Básica, a resistência dos professores é indissociável da luta pela defesa da educação escolar enquanto esfera singular do processo de formação humana, caracterizada pela inter-relação professor-estudante num determinado tempo-espaço. O processo educacional não significa apenas a transmissão de conhecimentos técnicos, mas também a construção coletiva de uma subjetividade sociocultural, a qual informa a tomada de decisões, inclusive, em relação à tecnologia e não pode estar desprovido de humanidade. 


\section{Referências}

ALBERTI, G. et al. Against and Beyond Precarity: Work in Insecure Times. Work, Employment and Society, [s.1.], v. 32, n. 3, p. 447-457, 2018. Disponível em: https://journals.sagepub.com/doi/10.1177/0950017018762088. Acesso em: 10 abr. 2020.

ALVES, T.; PINTO, J. M. Remuneração e Características do Trabalho Docente no Brasil: um aporte. Outros Temas, v.41 n.143, p. 606-639, maio/ago 2011. Disponível em: http://www.scielo.br/pdf/cp/v41n143/a14v41n143.pdf. Acesso em: 15 mai. 2019.

ANTUNES, R. O Privilégio da Servidão. São Paulo: Boitempo. 2018.

ANTUNES, R. Trabalho Intermitente e Uberização do Trabalho no Limiar da Indústria 4.0. In: ANTUNES, R. (Org.). Uberização, Trabalho Digital e Indústria 4.0. São Paulo: Boitempo. 2020.

BRASIL. Constituição da República Federativa do Brasil. Brasília, DF: Senado Federal/ Centro Gráfico, 1988.

BRASIL. Leis de Diretrizes e Bases. Lei no 9.394. 1996. Disponível em: http://portal.mec.gov.br/seed/arquivos/pdf/tvescola/leis/ lein9394.pdf. Acesso em: 10 abr. 2018.

BIMBATI, A. C. Qual é a situação dos professores brasileiros durante a pandemia?. Nova Escola, [s.1.], 1 jul. 2020. Disponível em: https://novaescola.org.br/conteudo/19386/qual-e-a-situacao-dos-pro fessores-brasileiros-durante-a-pandemia . Acesso em: 12 out. 2020. BOURDIEU, P.; PASSERON, J. C. A Reprodução. Elementos para uma teoria do sistema de ensino. Petrópolis. Rio de Janeiro: Vozes. 2013.

CARUSO, L. Digital Innovation and the Fourth Industrial Revolution: epochal social changes? AI \& Soc. v. 33. 2018. p. $379-392$. Disponível em: https://doi.org/10.1007/s00146-017-0736-1. Acesso em: 15 mai. 2019.

EDWARDS, R. Contested Terrain: The Transformation of the Workplace in the Twentieth Century. New York: Basic Books, 1979.

ENGUITA, F. M. A Escola Oculta: educação e trabalho no capitalismo. Porto Alegre: Artes Médicas. 1989.

EVANGELISTA, O; LEHER, R. Todos pela Educação e o episódio Costin no MEC: a pedagogia do capital em ação na política educacional brasileira. Revista Trabalho Necessário, v. 5, n. 15, 2012. Disponível em: http://www.uff.br/trabalhonecessario/images/ TN1519\%20Artigo\%20Roberto\%20Leher\%20e\%20Olinda\%20Evangelista.pdf. Acesso em: 12 fev. 2021.

FAGIANI, C. C. Brasil e Portugal: qual a formação do jovem trabalhador no século XXI? Uberlândia: Navegando, 2018.

FERRETTI, C. J. A reforma do Ensino Médio e sua questionável concepção de qualidade da educação. Estudos Avançados, v. 32, n. 93, p. 25- 42, 2018. Disponível em: https://www.scielo.br/pdf/ea/v32n93/0103-4014-ea-32-93-0025.pdf. DOI: 10.5935/01034014.20180028. Acesso em: 10 abr. 2019.

FREITAS, L. C. de. Três Teses sobre as Reformas Empresariais da Educação: perdendo a ingenuidade. Cad. Cedes, Campinas, v. 36, n. 99, p. 137-153, maio-ago., 2016. Disponível em: www.scielo.br/pdf/ccedes/v36n99/1678-7110-ccedes-36-99-00137.pdf. Acesso em: 20 ago. 2019.

FRIGOTTO, G. Empresários mais ricos do Brasil: a ignorância, o cinismo e a ganância que matam. Espaço e Economia. n.17, ano IX, 2020. Disponível em: http://journals.openedition.org/espacoeconomia/10852. Acesso em 05 jan. 2021.

GESTRADO. GRUPO DE ESTUDOS SOBRE POLÍTICA EDUCACIONAL E TRABALHO DOCENTE. Relatório Técnico Trabalho Docente em Tempos de Pandemia. Minas Gerais, 2020. Disponível em: https://gestrado.net.br/pesquisas/trabalho-docente-em-temposde-pandemia-cnte-contee-2020/. Acesso em: 15 out. de 2020.

GOTTI, A. Piso salarial para professor: ele existe, mas nem todo mundo paga. Nova Escola, [s.l.], 7 out. 2019. Disponível em: https:// novaescola.org.br/conteudo/18450/piso-salarial-ele-existe-mas-nem-todomundo-paga. Acesso em: 10 abr. 2021.

GRAMSCI, A. Notas sobre Maquiavel, a Política e o Estado Moderno, Rio de Janeiro: Civilização Brasileira, 1976.

GROHMANN, R. Plataformização do Trabalho: características e alternativas. In: ANTUNES, R. (Org.) Uberização, Trabalho Digital e Indústria 4.0 São Paulo: Boitempo. 2020. p. 93-110.

HARVEY, D. A Loucura da Razão Econômica. São Paulo: Boitempo. 2018

HARVEY, D. O Enigma do Capital. Boitempo: São Paulo. 2011.

HALL, D. GUNTER, H. A Nova Gestão Pública na Inglaterra: A Permanente Instabilidade da Reforma Neoliberal. Educação \& Sociedade, Campinas, v. 36, n. 132, p. 743-758, jul.-set., 2015. Disponível em: https://www.redalyc.org/pdf/873/87342690008.pdf. Acesso em: 15 abr. 2021.

HASSARD, J.; MORRIS, J. Contrived competition and manufactured uncertainty: Understanding managerial job insecurity narratives in large corporations. Work, Employment and Society, [s.1], v. 32, v. 3, p. 564-580. 2018.

HOOD, C. The "New Public Management" in the 1980s: Variations on a theme. Accounting, Organizations and Society. v. 20, n. 2/3, p. 93-109, 1995. Disponível em: https://www.sciencedirect.com/science/article/pii/0361368293E0001W. Acesso em: 14 mar. 2000.

HUWS, U. Working online, living offline: labour in the Internet Age. Work Organisation, Labour \& Globalization, [s.1], v. 7, n. 1, p. 1 - 11, 2013. Disponível em: https://doi.org/10.13169/workorgalaboglob.7.1.0001. Acesso em: 10 fev. 2021. 
IBGE. INSTITUTO DE GEOGRAFIA E ESTATÍSTICA. Desemprego. Rio de Janeiro, 2021. Disponível em: https://www.ibge.gov. br/explica/desemprego.php. Acesso em: 8 mai. 2021.

INEP. INSTITUTO NACIONAL DE ESTUDOS E PESQUISAS EDUCACIONAIS ANÍSIO TEIXEIRA. Educação Básica, Sinopses Estatísticas. Brasília: MEC, 2020 Disponível em: https://www.gov.br/inep/pt-br/acesso-a-informacao/dados-abertos/sinopses-estatisticas/ educacao-basica. Acesso em: 15 março. 2021.

KALLEBERG, A. L. Precarious Work, Insecure Workers: Employment Relations in Transition. Employment relations in transition. American Sociological Review, Chicago, v. 74, n. 1, p. 1-22, 2009.

LEHER, R. Universidades públicas, aulas remotas e os desafios da ameaça neofascista no Brasil. Carta Maior, Porto Alegre, 2020. Disponível em: https://www.cartamaior.com.br/?/Editoria/Educacao/Universidades-publicas-aulas-remotas-e-os-desafios-da-ameacaneofascista-no-Brasil/54/47699. Acesso em: 10 out. 2020.

LIMA, L. MEC autoriza ensino a distância em cursos presenciais. Portal MEC, Brasília, 18 mar. 2020. Disponível em: http://portal. mec.gov.br/busca-geral/12-noticias/acoes-programas-e-projetos-637152388/86441-mec-autoriza-ensino-a-distancia-em-cursospresenciais. Acesso em: 8 set. 2020.

NEWMAN; CLARKE, J. Gerencialismo. Educação e Realidade, Porto Alegre, v. 37, n. 2, p. 353-381, maio/ago. 2012. Disponível em: https://www.scielo.br/j/edreal/a/D9rWCZq8yqtBmtCTQSCjnPk/?lang=pt. Acesso em: 12 abr. 2021.

OLIVEIRA, D. Nova Gestão Pública e Governos Democrático-Populares: contradições entre a busca da eficiência e a ampliação do direito à educação. Educação \& Sociedade, Campinas, v. 36, nº 132, p. 625-646, jul.-set., 2015. Disponível em: https://doi.org/10.1590/ ES0101-73302015152440. Acesso em: 10 mai. 2020.

PREVITALI, F. S. FAGIANI, C. C. Diskiling and Degradation of labor in Contemporary Capitalism: the continuing relevance of Braverman. Work Organization, Labor and Globalization, v. 9, n. 1, p. 76-89, 2015. Disponível em: https://www.jstor.org/stable/10.13169/ workorgalaboglob.9.1.0076? seq=1. Acesso em: 20 abril. 2020.

PREVITALI, F. S. FAGIANI, C. C. Trabalho e Educação sob o Corona Vírus no Brasil. In: LUCENA, C.; PREVITALI, F.; BRETTAS, A. (Orgs.). Pandemia Covid-19: a distopia do século XXI. Uberlândia: Navegando, 2020a. p. 123 -136.

PREVITALI, F. S. FAGIANI, C. C. Trabalho Digital e Educação no Brasil. In: ANTUNES, Ricardo (Org.). Uberização, Trabalho Digital e Indústria 4.0. São Paulo: Boitempo. 2020b. p. 217-236.

RAMOS, M. N. A Pedagogia das Competências: autonomia ou adaptação? São Paulo: Cortez. 2001.

REUTERS. América Latina e Caribe: Covid-19. [Londres], 2021. Disponível em: https://graphics.reuters.com/world-coronavirustracker-and-maps/pt/regions/latin-america-and-the-caribbean/. Acesso em: 6 jul. 2021.

REVISTA LANCET: Brasil precisa dar uma resposta clara ao "E daí?" de seu presidente. Carta Maior, 8 maio 2020. Disponível em: https://www.cartamaior.com.br/?/Editoria/Politica/Revista-Lancet-Brasil-precisa-dar-uma-resposta-clara-ao-E-dai-de-seupresidente/4/47436. Acesso 8 mai. de 2020.

SAVIANI, D. Sobre a Natureza e Especificidade da Educação. Germinal: Marxismo e Educação em Debate, Salvador, v. 7, n. 1, p. 286-293, jun. 2015. Disponível em: https://drive.google.com/file/d/15xxR0AMcHZkeq1K6Ga94rfaUWoTLQtG8/view. Acesso em: 14 maio 2021.

SAVIANI, D. Trabalho e educação: fundamentos ontológicos e históricos. Revista Brasileira de Educação, Rio de Janeiro, v. 12, n. 34, p. 152-180, jan./abr. 2007. Disponível em: www.scielo.br/scielo.php?script=sci_arttext\&pid=S1413-24782007000100012 . Acesso em: 15 jun. 2017.

SHIROMA, E. O.; EVANGELISTA, O. Avaliação e responsabilização pelos resultados: atualizações nas formas de gestão de professores. Perspectiva. Florianópolis, v. 29, n. 1, p. 127-160, 2011. Disponível em: https://periodicos.ufsc.br/index.php/perspectiva/article/ view/2175-795X.2011v29n1p127. DOI: https://doi.org/10.5007/2175-795X.2011v29n1p127. Acesso em 10 fev. 2020.

SOTELO, A. Precariado ou Proletariado?. Marília/SP: Práxis, 2016.

SOUZA, A. N. de. Professores, Modernização e Precarização. In: ANTUNES, R. (Org). Riqueza e Miséria do Trabalho no Brasil II. São Paulo: Boitempo, 2016, p. 217- 228.

TOKARNIA, M. Quase metade das escolas não tem todos os itens de saneamento básico. Agência Brasil, Brasília, 22 jun. 2020. Disponível em: https://agenciabrasil.ebc.com.br/educacao/noticia/2020-06/quase-metade-das-escolas-nao-tem-todos-os-itens-desaneamento-basico . Acesso em: 8 set. 2021.

VENCO, S. Uberização do trabalho: um fenômeno de tipo novo entre os docentes de São Paulo, Brasil? Cadernos de Saúde Pública, n. 35. p. 1-17, 2019. Disponível em: http://www.scielo.br/pdf/csp/v35s1/1678-4464-csp-35-s1-e00207317.pdf. Acesso em: 13 out. 2019. WOODCOCK, J. O Panóptico Algorítmico da Delieroo: mensuração, precariedade e a ilusão do controle. In: ANTUNES, R. (Org.) Uberização, Trabalho Digital e Indústria 4.0. São Paulo: Boitempo. 2020. p. 23 - 46. 


\section{Notas}

1 A CPI do Covid-19 foi instaurada no Senado Federal por determinação do ministro do Supremo Tribunal Federal (STF), Luís Roberto Barroso em 8 de abril de 2021 e tem como objetivo apurar se houve falhas por parte do Governo Federal no enfrentamento da pandemia.

2 Composto pelos estados: São Paulo, Rio de Janeiro, Espírito Santo e Minas Gerais.

3 A CLT - Consolidação das Leis do Trabalho, data da 1943 e passou por diversas reformas. Porém a última, regulamentada pela Lei $\mathrm{n}^{\circ}$. 13.467 de 2017 sob o governo Temer, impactou fortemente a classe trabalhadora com a regulamentação do trabalho intermitente, das terceirizações de atividades fins e da livre negociação entre patrões e empregados, prevalecendo-se, como diz Antunes (2018), o negociado sobre o legislado.

4 O estado de Minas Gerais sob o governo de Aécio Neves (2003-2010) foi um dos primeiros a adotar a proposta gerencialista no âmbito de seu programa denominado "Choque de Gestão" em nome da eficiência administrativa e da racionalização dos gastos públicos.

5 O site da empresa é: http://www.biosferatech.com.br/blog/. Acesso em: 20 de jan. 2020.

6 O site da app: http://www.biosferatech.com.br/blog/2020/03/11/prof-e-inovacao-em-educacao-2/. Acesso em: 20 de jan. 2020.

\section{Fabiane Santana Previtali}

fabiane.previtali@gmail.com

Doutora em Ciências Sociais pela Universidade Estadual de Campinas (UNICAMP)

Professora na Universidade Federal de Uberlândia (UFU)

\section{UFU}

Av. João Naves de Ávila, 2121 - Santa Mônica,

Uberlândia - MG, Brasil

CEP: $38408-100$

\section{Cílson César Fagiani}

cilsoncf@gmail.com

Doutor em Educação pela Universidade Federal de Uberlândia (UFU)

Professor na Universidade de Uberaba (UNIUBE)

\section{UNIUBE}

Av. Afonso Pena, 1177 - Nossa Sra. Aparecida, Uberlândia - MG, Brasil

CEP: 38400-706

\author{
Agradecimentos \\ Agradecemos a leitura e as observações realizadas pelos \\ colegas do Grupo de Pesquisa Trabalho, Educação e Sociedade \\ - GPTES que muito contribuíram para elaboração final deste \\ artigo, todavia, ressaltamos que nos cabe a responsabilidade \\ pelas análises e conclusões apresentadas. \\ Agência financiadora \\ Fabiane Santana Previtali. \\ FAPEMIG, Processo: PPM-00061-17. Vigência: 22/09/2017 \\ 31/03/2023) \\ CNPq/PQ N-2, Processo: 303733/2018-7. Vigência: 2019 - \\ $2022 \mathrm{e}$ \\ CNPq/Universal, Processo: 422431/2018-4. Vigência: 2019 - 2022.
}

Cílson César Fagiani.

CNPq/Universal, Processo: 422451/2018-5. Vigência: 2019-2022 e FAPEMIG, Processo: APQ-01669-18. Vigência: 2018 - 2022. Contribuições das autoras

Ambos os autores são responsáveis pelas análises e conclusões do artigo.

Aprovação por Comitê de Ética e consentimento para participação

Não se aplica.

Consentimento para publicação

Consentimento dos autores.

Conflito de interesses

Não há conflito de interesses. 